\title{
Using ICT to overcome barriers to behaviour change and implement lifestyle interventions.
}

\author{
Amy Fielden \\ $\mathrm{PaCT} \mathrm{Lab}$ \\ Department of Psychology \\ Northumbria University \\ Newcastle-upon-Tyne, UK \\ amy.fielden@nothumbria.ac.uk,
}

\begin{abstract}
$\underline{\text { Abstract }}$
This paper outlines my doctoral research to date as well as describing areas for future research. The aim of my PhD is to explore the potential role that information and communication technologies (ICT) may have in motivating behaviour change relating to lifestyle behaviours. In particular the focus of my research are behaviours associated with obesity amongst those considered to be at high risk (families of low SES). Barriers to adopting healthy lifestyles will be explored and motivational techniques with strong theoretical underpinnings will be developed. ICTs will be considered and tested as means to disseminate motivational interventions. The research has a strong focus on real world applications which should be seen as highly important when focussed on addressing problems such as obesity.
\end{abstract}

Keywords-component; obesity, assistive technologies, internet family, diet, exercise, self affirmation, behaviour change.

\section{THE BACKGROUND TO THE RESEARCH}

The developed world is currently plagued by a wealth of diseases directly linked to modifiable aspects of our lifestyles, one such disease is obesity. Obesity is a result of economic wealth, high food availability, and more sedate leisure and low levels of physical activity. Technological progress has resulted in less human demand for energy but our biological systems have not evolved to accommodate this [1]. The Health Survey for England [2] illustrated that $65.9 \%$ of men and $56.9 \%$ of women have a Body Mass Index (BMI) higher than $25 \mathrm{~kg} / \mathrm{m}^{2}$, classing them as either overweight, obese (>30 $\left.\mathrm{kg} / \mathrm{m}^{2}\right)$ or morbidly obese $\left(>40 \mathrm{~kg} / \mathrm{m}^{2}\right)$. Obesity is linked to many chronic illnesses, including Type II Diabetes, heart disease and some cancers specifically bowel, and others within the digestive system [3]. As a result the direct cost to the National Health Service (NHS) of treating obesity was estimated to be between $£ 991-1124$ million, for the financial year 2001/2002 [4].

One surprising feature of the geographical distribution of obesity is its increased prevalence in economically and socially deprived areas in the developed world. This phenomenon is very much a recent development, because historically deprived areas tended to see higher levels of under-nutrition and under-weight. Research [5], illustrates how this situation has now reversed. They found between
1995 and 2005 the gap between obesity levels in the most deprived areas compared to the least (the latter typically having the higher levels) was decreasing and that by 2005 obesity levels in the most deprived areas had overtaken those in the least deprived areas, a phenomenon that persists today.

Government research [1] concluded the majority of interventions are failing, and that simply educating individuals about both the short and the long term consequences of obesity is not enough to change behaviour.

For example evidence suggests there is a ceiling effect in solely educating children about the importance of healthy lifestyles. Children have been a primary target of obesity interventions mainly due to the rapid increase in recent years of overweight and obese children. Researchers and health professionals argue that the future will see many children dying before their parents, because of diseases resulting from obesity [6]. However a review of interventions to target childhood obesity has highlighted the importance of parents and caregivers. Interventions show greater beneficial effects when behaviour change techniques were taught to both parents and children [7]. This highlights the need for interventions to be delivered into the home, where the potential audience is both the children and the parents (who should be viewed as the primary decision maker in lifestyle choices).

An increase in the use of information and communication technologies (ICT) has often been cited as a contributing factor in the rise in prevalence of obesity $[8,9]$. For example, [10] demonstrated that time spent watching television is associated with childhood and adolescent obesity.

However, the internet is an increasingly popular mode by which to deliver health interventions. The reasons for this suggested by [11] include; reducing costs, increasing convenience for users, reaching isolated or stigmatised groups and the timeliness of access to the internet. In terms of the obesity problem, overweight and obese individuals often feel stigmatised and subsequently become isolated [12]. In addition given the direct and indirect costs of obesity, low cost, high impact interventions must be considered the most attractive to policy makers and stakeholders. The internet may prove a viable means to deliver lifestyle behaviour interventions to an increasing proportion of the population. 
Recent government statistics [13] demonstrate that in 2010 $73 \%$ of UK households had internet access, this equates to 19.2 million homes. There are also publicly available internet access points and an increasing use of the internet on mobile phones. They also reported that $60 \%$ of the population use the internet on a daily basis and the majority of those who do not are over 65 . It can be argued that the majority of the target population in this ongoing research project (families with school aged children of low SES) will or should have access to the internet. This project will also collect data relating to the technology use amongst a group of parents of low SES in order to explore if the internet as a viable means to deliver interventions to this high risk group. The delivery of interventions online needs to focus on motivating and supporting behaviour change rather than indirectly increasing time individuals spend being sedentary.

\section{THE SPECIFIC PROBLEM THE RESEARCH WILL ADDRESS}

As with many of today's biggest killers, obesity as a condition is considered the result of an interaction between genetic predeterminants and environmental triggers [1]. The importance of environmental factors in the onset of obesity means there is a large scope for preventing the condition through making lifestyle behaviour changes. However despite this knowledge being widely disseminated in the public domain many individuals struggle to make the necessary changes to their diet and exercise regimes and "diseases of lifestyle" continue to rise worldwide [14]. In addition, as established previously, these lifestyle diseases are particularly common amongst those of low SES. Other research $[15,16]$ has demonstrated that the simple presentation of health related information often fails to persuade individuals to modify their behaviour.

The research reported in this paper is part of a three year project exploring the obesity problem and the potential mode by which technology may be used in delivering successful interventions. Furthermore, in response to criticisms of interventions and studies failing to describe their theoretical underpinnings [7], the studies undertaken are based on existing psychological theories.

The research questions proposed to date are; What do parents understand about their own and their children's lifestyle behaviours, and what role do technologies play in their lives? (Study one)

Do parents from different SES identify the same barriers to healthy living? (Study two) Can Self Affirmation manipulations be delivered online, and will they result in a greater intention to change behaviour than receiving health information alone? (Study three)

\section{THE METHODOLOGICAL APPROACH}

The research will entail a pragmatic research methodology adopting a mixed methods framework. The use of both qualitative and quantitative methodologies will allow exploration and empirical work to be undertaken. To increase ecological validity the majority of participants will be sought from the general public in particular families with school aged children.

\section{THE WORK DONE TO DATE}

Study One

This study was a series of interviews with 8 participants (4 mothers and 4 fathers) all had at least two children and the participants were judged to be of low SES (through occupation and area of residence).

The main focus of the interviews was to determine aspects of their day-to-day life with particular emphasis on time for and types of physical activity and time for and types of food consumed. In addition, the use of, and access to technologies within a family setting was discussed. Interview questions were also designed to identify aspects of the participants' knowledge about diet and exercise and it's relation to health in general.

The main findings of this study were that the participants appeared to have an accurate knowledge relating to diet and physical activity and they were aware of many of the recommendations made by the government and its agencies in relation to these behaviours. However discussions focussing on the participants' day-to-day life revealed that knowledge and behaviour did not match up. They were able to explain the barriers they felt existed to adopting healthier lifestyles stating 'time', 'money', 'fussy children' and 'unsafe' local environments hindered their adherence to healthful behaviours. Furthermore, the participants were all aware of the importance of their children's health but moreover, were conscious of their role as care givers in their children's lifestyles.

It was apparent that most activities within the family home required the use of some sort of technology, which included the television, games consoles, computers and the internet. Interestingly even though not all of the participants had "always on" broadband they all had internet enabled mobile devices or used pay as you go mobile internet on their home computers and laptops. This supported the notion that the internet may prove to be a viable means of disseminating interventions.

\section{Study Two}

This study is currently ongoing. The interview data collected from the parents in study one was used to compile a set of 66 Q-Sort statements. The statements reflected the attitudes expressed by the participants in study one with regards to the barriers they felt hindered their adoption of healthier lifestyles and the ways in which they use technology in the home. Participants for this study are also parents of school-aged children in this case of medium to high SES. The aim is to collect between 20 and 30 Q-Sorts.

Parents are completing a Q-Sort with the statements provided. A computer programme (PCQ for Windows) will be used to analyse the data. The analysis will produce groups of participants who have sorted the statements in similar ways. Representative sorts will then be verified and validated by showing them to relevant participants. 
It is anticipated that the parents of higher SES will not identify the same barriers to healthy lifestyles as those in study one. Data collection is still ongoing at the time of writing.

\section{Study Three}

This study focuses on the delivery of an established method of intention and behavior modification; Self Affirmations (SA), online.

Self Affirmation Theory [17] proposes that people are fundamentally motivated to protect themselves as 'adaptively and morally adequate', therefore when they receive information that threatens their view of themselves they respond in a biased and defensive manner [18]. Through reflecting on one's cherished values, actions and attributes, self affirming reinforces an individual's sense of who they are. This acts as a defence mechanism, or repair tool when they receive threats to their identity. Self affirming has been shown to be an effective means by which to promote behaviour change in the health domain [14]. Most recently it has been shown to be an effective tool to increase fruit and vegetable consumption [19]. These findings are particularly relevant for this current research project, as it was demonstrated that the effects of self affirming are not limited to promoting message acceptance but extend to actual health behaviour The primary aim of this study was to successfully deliver an SA manipulation online, adapting the methods in [19]. This was measured by the self affirmation check described in [20]. The control condition employed a set of questions relating to participants opinions. A secondary aim was to demonstrate that those participants in the SA condition score higher on a measure of intent to change behaviour than those in the control condition.

It was hypothesized that those participants in the experimental condition and exposed to the SA manipulation would score significantly higher on the SA check than those participants in the control group. In addition it was hypothesized that the participants in the experimental (SA condition) would score significantly higher on measures of intent to change their behaviours than the control group.

Undergraduate psychology students $(n=58)$ participated in the study. They were informed that they were taking part in a series of studies looking at the communication of health information online, personality beliefs.

The computer programme randomly assigned the participants to either the control condition or the experimental condition.

The programme then guided the participants through a series of measures;

Readiness to Change was gauged via an adapted measure from [21]. This showed that the majority (71\%) of participants were in the stages up to and including 'action', this was the same in both conditions.

Self Affirmation Manipulation poses a series of questions such as; "Have you ever forgiven another person when they hurt you". When participants gave a yes answer they were asked to type an account of this experience.
Personal Opinions Question- "I think chocolate is the best flavour of ice cream". When answering yes they were asked to explain why.

A health message was developed from government websites relating to eating 'five a day' and physical activity, information and included benefits, recommendations, consequences of unhealthy lifestyles and suggestions for improving the relevant behaviour.

Intentions were measured by two questions such as; "Do you intend to eat at least 5 portions of fruit and vegetables each day in the next seven days" and "I intend to do at least 30 minutes of exercise three times a week over the next seven days". Responses were measured on a 7 point scale. A manipulation check [20] was included to ensure participants in the experimental condition had Self Affirmed.

As a guise a recall test was also included. Participants were presented with a series of words and had to say whether or not they had appeared in the health information. This was important as if individuals are aware of the process it won't work [18].

In terms of the first study aim to successfully deliver a SA manipulation online, participants in the experimental condition scored significantly $(\mathrm{p}=0.01)$ higher on the manipulation check. This suggests the participants in the experimental condition had Self Affirmed. Participants in the SA condition scored significantly higher $(\mathrm{p}=0.002)$ on the intent measure than those in the control group. This suggests the SA manipulation is associated with an increase in intent to change behaviour.

Therefore this study was successful in its aims to deliver a SA manipulation online, and to replicate the findings of other SA studies where the manipulation has increased intent. These are promising results and provide scope for much future research, which is outlined below.

\section{CONTRIBUTION}

The main contribution of this work is developing a method by which empirically supported psychological theories can be applied in a real world setting. The internet and other potential technologies will be used to do this as they offer an increasingly viable means to reach the target population. Furthermore the project will provide evidence for the potential use of technologies in addressing a problem, which they are often cited as contributing to.

\section{FUTURE WORK}

The next stage of research will focus on two areas. The findings of studies one and two will be used to identify barriers which parents identify in adopting healthier lifestyles. It is anticipated that by identifying these issues normally tied up in aspects of everyday life, messages can be developed that coherently and effectively offer solutions to overcoming such barriers. This information can in turn be incorporated into future work focussing on Self Affirmations as it will allow more specific health messages and suggestions for change within those health messages to be applied within the SA manipulation. 
The second area of future research will focus on refining and developing the SA online programme. It is intended that the next study will focus on demonstrating actual behaviour change in a set of participants. This will involve replicating the work in [19] and will focus on one lifestyle behaviour such as fruit and vegetable consumption. This research will require baseline fruit and vegetable consumption measures and then post manipulation consumption to be measured.

Technological devices are being explored in order to enable easy and accessible recording of this data. It is also apparent that the SA manipulation programme needs to be refined so that it is shorter to complete. In addition, future studies must consider the most appropriate method to present health messages and should employ methods of self affirming that perhaps do not rely so heavily on the participant having strong literacy skills as many parents of low SES report low literacy skills.

\section{SPECIFIC ISSUES FOR THE DOCTORAL CONSORTIUM}

It would be of benefit to this research project to address issues surrounding both the background to my research and also the practicalities of the intended future work.

This research brings together several different fields of research; the obesity problem and why it exists; the use of technology to deliver and disseminate health messages and also empirically based psychological theories of motivation and behavior change. This can at times be problematic as it requires consideration of a number of factors; discussions around cross discipline research and strategies that can be taken to make it more feasible would benefit this project greatly.

In addition there is a strong focus within this research to recruit participants from the target population. This not only helps to ensure ecological validity but also strengthens the application of the research in a real world setting. However recruiting and working with participants in this manner can be difficult and it would be interesting to raise this as an issue to discuss.

Further points for discussion include; how feasible is it to use technologies such as the internet to motivate people and is it ethical? And, should we be considering if the use of personalised systems would be more beneficial e.g. an app for mobile phone or would this prove to be an ineffective means of reaching the target population?

\section{ACKONWLEDGMENTS}

I am grateful to Dr. Linda Little and Dr Liz Sillence for their support and advice in supervising this project. I also appreciate the guidance and support of Dr. Lynne Coventry Prof. Peter Harris and Andre Bester.
[1] Department of Innovation Universities and Skills, "Foresight-Tackling Obesities: Future Choices and Project Report," Government Office for Science, London, 2007.

[2] The NHS Information Centre, "Statistics on Obesity, Physical Activity and Diet: England," The Information Centre for Health and Social Care. London:NHS, 2009.

[3] Renehan, A. G., Tyson, M., Egger, M., Heller, R. F. \& Zwahlen, M, "Body-mass index and incidence of cancer: a systematic review and meta-analysis of prospective observational studies," The Lancet, 371 (9612), pp.569-578, 2008.

[4] McCormick, B. and Stone, I, "Economic Costs of Obesity and the Case for Government Intervention," Obesity Reviews, 8(1), pp.161-164, 2007.

[5] Brunt, H., Lester, N., Davies, G. \& Williams, R, "Childhood overweight and obesity: is the gap closing the wrong way?" Journal of Public Health, 30 (2), pp.145, 2008.

[6] Vlad, I, “Obesity costs UK economy £2bn a year,” BMJ, 327 (7427), pp. 1308, 2003.

[7] Mclean, N., Griffin, S., Toney, K. and Hardeman, W, "Family Involvement in weight conrol, weight maintenance and weight loss interventions: a systematic review of randomised trials," International Journal of Obesity. 27, pp.987-1005, 2003.

[8] Gortmaker, S, L., Must, A., Sobol, A, M., Peterson, K., Colditz, G, A. and Dietz, W, H, "Television Viewing as a Cause of Increasing Obesity Among Children in the United States, 1986-1990," Archives of Paediatric and Adolescent Medicine. 150, pp.356-362, 1996.

[9] Hernandez, B, Gortmaker, S,L., Colditz, G, A., Peterson, K,E., Laird, N, M. and Parra-Cabrera, S, "Association of Obesity with Physical Activity, Television Programs and other Forms of Video Viewing among Children in Mexico city," International Journal of Obesity Related Metabolic Disorders. 23, pp.845-854, 1999.

[10] Kaur, H., Choi, W, S., Mayo, M, S. and Harris, K, J, "Duration of Television Watching is Associated with Increased Body Mass Index," Journal of Paediatrics. 143, pp.506-511, 2003.

[11] Griffiths, F., Lindenmeyer, A., Powell, J., Lowe, P. \& Thorogood, M, "Why are health care interventions delivered over the internet? A systematic review of the published literature," Journal of Medical Internet Research. 8 (2), e10, 2006.

[12] Puhl, R. \& Brownell, K. D, "Bias, Discrimination, and Obesity," Obesity. 9 (12), pp. 788-805, 2001.

[13] Internet Access 2010- Households and individuals: Statistical Bulletin. Office for National Statistics URL: http://www.statistics.gov.uk/pdfdir/iahi0810.pdf. Accessesd 07/02/2011

[14] Harris, P. and Epton, T, "The Impact of Self Affirmation on Health Cognition, Health Behaviour and other Health Related Responses: A Narrative Review," Social and Personality Psychology Compass. 3(6), pp.962-978, 2009.

[15] Blumberg, S, J, "Guarding against threatening HIV prevention messages: An information-processing model," Health Education \& Behavior. 27, pp.780-795, 2000

[16] Jacks, J, Z. and Cameron, K, A, "Strategies for Resisting Persuasion," Basic and Applied Social Psychology. 25, pp.145-161, 2003.

[17] Steele, C, M, "The psychology of self-affirmation: Sustaining the integrity of the self," in L. Berkowitz (Ed.), Advances in Experimental Social Psychology. 21, pp.261 - 302, 1988.

[18] Sherman, D, K. \& Cohen, G, L, "The Psychology of Self-defence: Self Affirmation Theory," Advances in Experimental Social Psychology. 38, pp. 183-242, 2006.

[19] Epton, T. and Harris, P, R, "Self-affirmation Promotes Health Behaviour Change," Health Psychology, 74, pp. 746-752, 2008.

[20] Napper, L., Harris, P. R. \& Epton, T, "Developing and testing a selfaffirmation manipulation," Self and Identity, 8 (1), pp. 45-62, 2009.

[21] Laforge, R. G., Greene, G. W. \& Prochaska, J. O, "Psychosocial factors influencing low fruit and vegetable consumption," Journal of Behavioral Medicine, 17 (4), pp. 361-37, 1994.

\section{REFERENCES}

